\title{
Impact of Organizational Citizenship Behavior on Role Conflict: A Study of a Leading Paints Manufacturing Company in Sri Lanka
}

\author{
H. M. S. V. Silva ${ }^{1}$ and W. A. C. U. K. Ranasinghe ${ }^{2}$ \\ ${ }^{1,2}$ Department of Human Resource Management, Faculty of Commerce and \\ Management Studies, University of Kelaniya, Sri Lanka \\ 1'michellevindya@kln.ac.lk, ${ }^{2}$ chamarauk385@gmail.com \\ iD https://orcid.org/0000-0003-3811-3011
}

\begin{abstract}
The purpose of this study was to investigate the impact of Organizational citizenship behavior (OCB) on Role conflict in a leading paint company Sri Lanka. This is a quantitative study conducted within the positivistic research philosophy using the deductive approach. This study was carried out as cross sectional study with a sample of 150 operational level employees who are directly engaged with the production process. Simple random sampling and survey strategy was followed in the study. A self-administered, anonymous, pre-tested questionnaire was used for data collection purpose. A theoretical basis for a relationship between OCB and role conflict was identified using Role theory. The first hypothesis was tested using multiple regression analysis and it was possible to conclude that there is a that $60 \%$ of the variance in role conflict of operational level employees is explained by organizational citizenship behavior alone. The dimensional analysis was conducted to test sub hypotheses of $\mathrm{H} 1$ and it revealed that civic virtue as a most influential dimension $(\beta=.580, p<0.05) \quad$ of OCB on role conflict of operational level employees. As the number of studies testified OCB on role conflict in the Sri Lankan context is limited the present findings have implications for researchers and practitioners to identify efforts that work toward increasing commitment of team members, thereby increasing organizational citizenship behavior in the organization.
\end{abstract}

Keywords: Organizational Citizenship behavior, Role Conflict, Role theory

\section{Introduction}

A role is the set of behaviors that others expect of individuals in a certain context (Katz \& Kahn, 1978). Role conflict is defined in terms of the dimensions of congruency-in congruency or compatibility incompatibility in the requirements of the role, where congruency or compatibility is judged relative to a set of standards or conditions which impinge upon role 
performance. Over the past 50 years, researchers have given considerable attention to the ways in which roles affect employee behavior (Jackson \& Schuler, 1985; Katz \& Kahn, 1978). Role theory suggests that people generally seek to behave in ways that are consistent with the way their roles are defined (Kahn, Wolfe, Quinn, Snoek, \& Rosenthal, 1964). Role conflict measures the degree of role stress an individual experience in a domain (Kacma, 2000). This theory found both conflict and ambiguity in different roles to be clearly associated with low job dissatisfaction and dysfunctional behavior due to the stress and anxiety of role pressure. When individuals interact within well-defined roles, their interactions become more predictable, which increases the level of mutual trust in the organization (Mayer, Davis, \& Schoorman, 1995). Because trust leads to greater openness, information sharing, and learning (Argyris, 1976), high trust makes relational exchanges more efficient. In the absence of clear roles, however, interactions are less predictable, and the trust needed within the group is more difficult to develop. Furthermore, the less clearly defined the roles, the greater the stress created by role conflict and the more likely it is that individuals will use avoidance, lying, or organizational exit to cope with the stress (Biddle \& Thomas, 1966).

Although the primary information flows within renewal are vertical, information also flows later- ally within management levels to coordinate both operational and strategic activities. Middle managers attempting to champion a strategic initiative, for example, may need to develop political support from other middle managers in advance of making a formal proposal to top management. Therefore, exchanges may involve managers at the same level in different parts of the organization. In some cases differences in the orientation of subunits may cause different perceptions about the need for change (Walsh, 1988), which increases the uncertainty surrounding exchanges between managers in these subunits (Lewis \& Weigert, 1985), thereby heightening the risk of role conflict.

Organizational citizenship behavior (OCB) refers to employee behavior that is extra-role, that promotes organizational effectiveness, and that is not explicitly recognized by an organization's reward system (Organ, 1988). Literatures in the past have identified two main approaches known as "role" and "extra-role behavior" in defining the concept of OCB. Extra role means the individual contributions in the workplace which go beyond the specified 
role requirements and not recognized by the reward system. Castro, Armario, and Ruiz (2004) concluded that it is not easy for a firm to differentiate between "role" and "extra role" performances as managerial and employee perceptions of their subordinates' performances do not correspond and subject to the satisfaction of the subordinates in the workplace. A great deal of researches have suggested that there are five basic personality factors which affect most of the variance in personality (e.g., Costa \& McCrae, 1992) and these dimensions are known as Big Five dimensions which are classified as conscientiousness, altruism, courtesy, sportsmanship, and civic virtue. Hence, this study adopts the Organ's initial definition of OCB with five dimensions.

It is widely believed that organizations could not survive unless employees were willing to occasionally engage in OCB (Katz \& Kahn, 1978). Katz argued (1978) that an organization unable to depend upon employee extrarole behavior is 'a very fragile social system' (p. 132). Organ (1997) defined organizational citizenship behavior (OCB) as "contributions to the maintenance and enhancement of the social and psychological context that supports task performance" (p. 91). Typically, then, employees who engage in OCBs are those who go the extra mile for their organizations and thereby contribute to its effective functioning. Prior research on OCB has generally focused on one of the following two areas. First, a number of studies have sought to identify the antecedents of citizenship behavior (LePine, Erez, \& Johnson, 2002).

Research along these lines has suggested that employees, who are satisfied with their jobs, are committed to their organizations, and feel they are treated fairly are likely to engage in OCBs (Organ \& Ryan, 1995). In addition, other research has indicated that employees who are given satisfying tasks and work for transformational or supportive leaders are also likely to exhibit OCBs (Podsakoff, MacKenzie, Paine, \& Bachrach, 2000). Clearly, previous work in this area has broadened our understanding of the antecedents of OCB and the implications of such behavior for the effective functioning of organizations. As noted by Organ and Ryan (1995), few studies have sought to understand the potential implications of OCB for employees. Moreover, whereas citizenship behavior may affect organizations in several positive ways, it is also possible that engaging in such behaviors could have negative 
consequences for the employees who do so. In particular, Organ and Ryan (1995) suggested that being a good organizational citizen could contribute to employee stress and overload. In addition, there may be other personal costs (such as work-family conflict) that accrue to individuals who engage in high levels of citizenship behavior. To date, however, the idea that OCBs could have a negative impact on the employees who perform them has largely been ignored. This omission is particularly troubling because the findings of a number of recent studies have indicated that, increasingly, employers are asking their employees to put forth more effort, work longer hours, and be more accessible. Indeed, contemporary organizations see the ideal worker as one who "works full time and overtime and takes little or no time off for childbearing and child rearing" (p. 1). That is, the ideal worker is an employee who not only demonstrates high levels of task performance but also engages in high levels of contextual performance or OCB as well.

However, whereas being a "good soldier" is a reality for many employees today, there have been few studies investigating the ways in which the "good soldier syndrome" (Organ, 1988) might affect those employees personally. This research, then, explores how a specific type of OCB individual initiative may contribute to employee stress and strain on the other hand role conflict. In doing so, this study has two principal goals. First, this investigation explores the possibility that high levels of individual initiative may affect employees in negative ways. Individual initiative is a specific type of OCB in which employees "engage in task-related behaviors at a level that is so far beyond minimally required or generally expected levels that it takes on a voluntary flavor" (Podsakoff et al., 2000, p. 524). Examples of individual initiative might include going into the office on weekends, coming in early for work (or staying late), volunteering for special projects in addition to one's normal job duties, and so on. As noted by Organ (1988) many of the behaviors composing individual initiative could be considered in-role; however, it is the "marked level or intensity" of these behaviors that make them qualify as a type of citizenship. Thus, the first hypothesis of this study is as follows.

$\mathbf{H}_{1}$ : There is a significant impact from Organizational citizenship behavior on role conflict. 
Conscientiousness is used to indicate that a particular individual is organized, accountable and hardworking. Organ (1988) defined it as dedication to the job which exceed formal requirements such as working long hours, and volunteer to perform jobs besides duties. In addition to that, studies have also revealed that conscientiousness can be related to organizational politics among employees (McCrae \& Costa, 1987). Kidder and McLean Parks (1993) posited the fact that males are more like to engage in conscientious behavior than females. Moreover, they identified that less conscientiousness lead for role conflict. Thus, the first sub hypothesis under $\mathrm{H} 1$ is as follows.

$\mathbf{H}_{\mathbf{1} \mathbf{a}}$ : There is an impact of conscientiousness on role conflict

Organ (1988) defined sportsmanship as the behaviour of warmly tolerating the irritations that are an unavoidable part of nearly every organizational setting. Podsakoff and MacKenzie (1997) revealed that good sportsmanship would enhance the morale of the work group and subsequently help employees to reduce the ambiguity in the different roles he/she has to play. Thus, the second sub hypothesis is as follows.

$\mathbf{H}_{\mathbf{1 b}}$ : There is an impact of sportsmanship on role conflict

Civic virtue is defined as subordinate participation in organization political life and supporting the administrative function of the organization (Deluga, 1998). It is referring to the responsibility of the subordinates to participate in the life of the firm such as attending meetings which are not required by the firm and keeping up with the changes in the organization (Organ, 1988). This dimension of OCB is actually derived from Graham's findings which stated that employees should have the responsibility to be a good citizen of the organization (Graham, 1991).These behaviors reflect an employees' recognition of being part of organization and accept the responsibilities which entails (Podsakoff et al., 2000). Other researchers have found that civic virtue enhances the quantity of performance and help to reduce customer complaints and lead for role conflict (Walz \& Niehoff, 1996).Thus, the third sub hypothesis of this study is as follows.

$\mathbf{H}_{1 \mathbf{c}}$ : There is an impact of civic virtue on role conflict 
Courtesy includes behaviors, which focus on the prevention of problems and taking the necessary step so as to lessen the effects of the problem in the future. In other words, courtesy means a member encourages other workers when they are demoralized and feel discouraged about their professional development. Early research efforts have found that employees who exhibit courtesy would reduce intergroup conflict and role conflict. Thus, thereby diminishes the time spent on conflict management activities (Podsakoff et al., 2000). Thus, the fourth sub hypothesis of this study is as follows.

$\mathbf{H}_{1 \mathbf{d}}$ : There is an impact of courtesy on role conflict

Smith, Organ, and Near (1983) defined altruism as voluntary behaviors where an employee provides assistance to an individual with a particular problem to complete his or her task under unusual circumstances. Altruism refers to a member helping other members of the organization in their work. Podsakoff et al. (2000) has demonstrated that altruism was significantly related to role conflict and high altruism will lead for low conflict among the roles that the particular employee has to perform. Thus, the fifth sub hypothesis of this study is as follows.

$\mathbf{H}_{\mathbf{1 e}}$ : There is an impact altruism on role conflict

Based on above four hypotheses, the conceptual framework of the study is as follows. 


\section{Figure 01: Conceptual Framework of the Study}

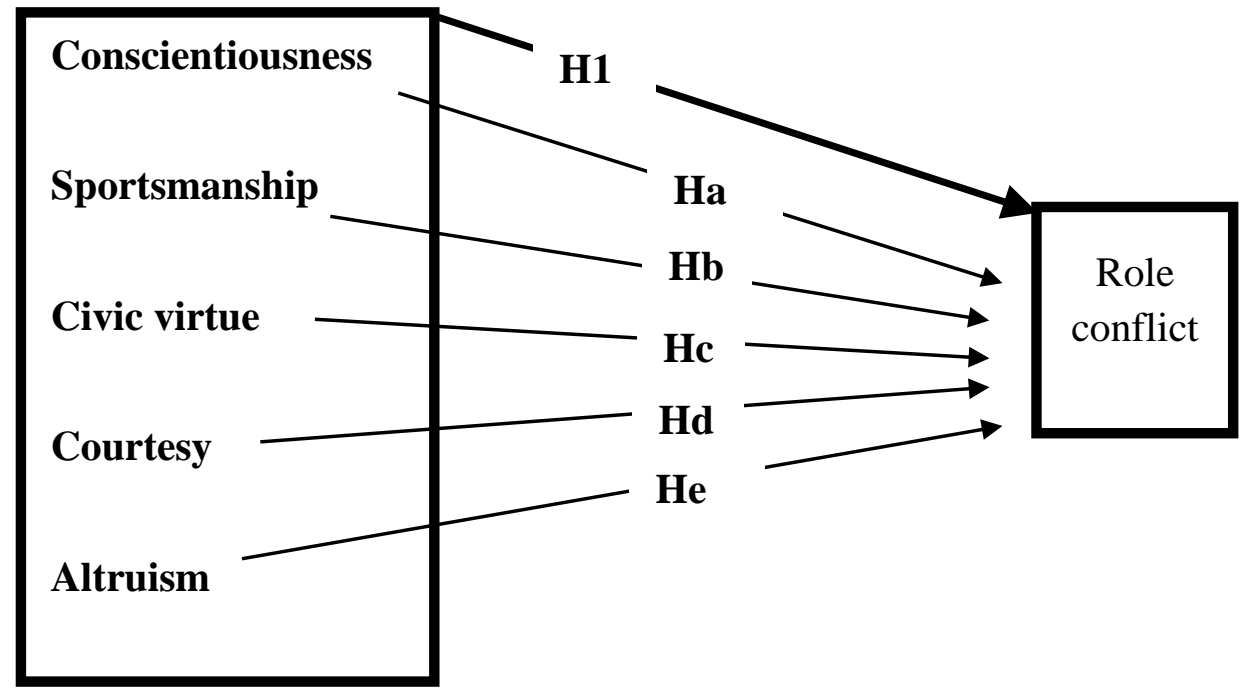

Source: Authors (2016)

\section{Methods and Materials}

Research is a process that investigates and determines reasons for a topic to be further studied in order to describe, explain, predict and control an observed phenomenon with a view to increasing knowledge. Saunders et al. (2011) also explained the importance of the research paradigm in research as it is the framework which guides and supports how research should be conducted. In addition, Collis and Hussey (2009) recognized the foundations of the research paradigm are based on the attitudes and beliefs of people towards the world and the nature of knowledge. They identified that there are two types of research paradigms. They are positivism and interpretivism which provide context for the research methodology. Accordingly, this study is entitled on 'The Impact of Organizational Citizenship Behavior on Role Conflict: A Study on one of a leading paint company in Sri Lanka takes a positivism approach which attempts to investigate, confirm and predict patterns of behavior in social reality. Moreover, Creswell (1994) has given a very concise definition of quantitative research as a type of research that is "explaining phenomena by collecting numerical data that are analyzed using mathematically based methods (in particular statistics)" (p.5). As this is an 
explanatory study, researcher has selected a quantitative research method which provides a greater opportunity to engage with a larger number of respondents for generalization as opposed to a qualitative approach.

As the research context, researcher has selected one of leading Paint Company in Sri Lanka. This was cross-sectional study since data was collected in a particular point of time and it did not repeat. Accordingly, survey strategy was followed and self- administered questionnaire was used as the data collection instrument. Organizational citizenship behavior was measured using the five-point scale developed by Podsakoff \& MacKenzie (1994). Role conflict was measured using five-point scale developed by Rizzo,House, and Lirtzman (1970).

In addition, pilot test was conducted prior to the distribution of the final version of the questionnaire to target population and 30 questionnaires were distributed among the sample population. Moreover, respondents were assured that all responses of them would be strictly anonymous and encouraged them to answer the questions as truthfully as possible. This study was carried out using survey strategy and pretested- self-administered questionnaire was distributed among 150 operational employees and they were considered as the potential respondents of this study. This study has used the simple random sampling technique to select the respondents even 150 were distributed 150 only received 136 in return. But out of the received questionnaires, only 122 were usable since other two had high missing values. The response rate was $72 \%$ and which was acceptable.

\section{Data Analysis and Presentation}

\subsection{Demographic Information}

There are $97.5 \%$ of male employees and $2.5 \%$ are female employees in this study. Majority (75.4\%) of them are married, only $24.6 \%$ are single. Further, most (39.3\%) are in age between 26-35 years. Majority $(48.4 \%)$ of employee's length of service at the current position is in between 2-5years and only $22.1 \%$ of them having less than two years' experience at their current position. Moreover, majority of the employee (65.6\%) have completed G.C.E. ordinary level examination and only $16.4 \%$ have completed G.C.E advanced level examination. 


\subsection{Preliminary Analyses}

Preliminary analysis is required to perform before testing hypothesis.

Checking the accuracy of data entry can be ensured by looking for illicit codes. Each usable questionnaire was given a unique code number, and it was used to do a random check to ensure exact details are entered. 'Range' is checked for items of variables and demographic information to ensure entry accuracy. In the data set of this study there were only seven missing data which are Missing Completely At Random (MCAR). In order to address them, manually calculated replacement value considering the mean of the non-missing values is used for seven missing values.

With regard to the normality of data, Kline (2005) established a rule of thumb for skew index of absolute value less than 03 and kurtosis value less than 10 was used to test the normality of the data distribution. Accordingly, results indicate that the sample data is normally distributed and data transformations available to address problems of normality in non -normal distribution as stated by Hair et al., (2012) are not required for this study. Scatter plot diagram and residual plots were drawn to examine linearity between variables. In scatter diagrams, scatter plots took an approximately oval shape according to the visual inspection.

\section{Table 01: Reliability Statistics}

\begin{tabular}{ll}
\hline & Cronbach's Alpha \\
\hline OCB & .769
\end{tabular}

Role Conflict .834

Source: Survey Data (2016)

Reliability is defined by Field (2009) as the ability of an instrument or a measure to be interpreted consistently across different situations. Cortina (1993) recommends that instruments used in a basic research have a reliability of about .7 or better, and states that values substantially lower indicate an unreliable scale. With regard to the reliability of constructs, Cronbach alpha values of each constructs were used to test the reliability. Accordingly, all 
values of reliability are greater than 0.7 which show high reliability in measures.

According to Hair et al. (2010), the most common method of assessing linearity is the visual examining of bivariate scatter plots of the variables and identifying nonlinear patterns in data.Thus, scatter plot diagram and residual plots were drawn to examine linearity between variables. In scatter diagrams, scatter plots took an approximately oval shape according to the visual inspection. Finally, that straight line relationships exist between all variables and the assumption of linearity can be assured. According to Hair et al. (2010), the standardized factor loading estimates of the measurement model should be .5 or higher and ideally .7 or higher to ensure construct validity. Accordingly, all the standardized regression weights for items in the measures are above .5 and these estimates denote that the indicators are related to the associated variables and approves construct validity in this study.

Variance inflation factor (VIF) values and tolerance values are used to check the multicollinearity of this study. Hair et al. (2010) defined VIF as the amount of variability of the selected independent variable not explained by the other independent variables. "The VIF indicates whether a predictor has a strong linear relationship with the other predictor(s)" (Field, 2009, p. 224). The figures of the study (VIF=5, Tolerance $=.23$ ) indicate that the tolerance is far greater than .1 (Field, 2009) and the VIF is far less than 10 for each predictor (Field, 2009). These values reveals that no multicollinearity between independent variables and assure that remedial actions are not required as well. 


\subsection{Hypothesis Testing}

Table 02: Measuring the Impact of OCB on Role conflict

\begin{tabular}{ccc}
\hline Model & Standardized Coefficients & t \\
& Beta & Sig. \\
\hline
\end{tabular}

Organizational Citizenship Behavior .773

a. Dependent Variable: Role Conflict

Source: Survey Data (2016)

Table 03: Model Summary

\begin{tabular}{ccccccc}
\hline & & & & \multicolumn{3}{c}{ Change Statistics } \\
Mode & $\mathrm{R}$ & $\mathrm{R}$ & Adjusted $\mathrm{R}$ \\
Square & Square & $\begin{array}{c}\text { R Square } \\
\text { Change }\end{array}$ & $\begin{array}{c}\mathrm{F} \\
\text { Change }\end{array}$ & $\begin{array}{c}\text { Sig. F } \\
\text { Change }\end{array}$ \\
\hline & $.773^{\mathrm{a}}$ & .597 & .594 & .597 & 177.723 & .000
\end{tabular}

a. Predictors: (Constant), Organizational Citizenship Behavior

Source: Survey Data (2016)

\section{$H_{1}$ : There is an impact from Organizational Citizenship Behavior on Role conflict.}

According to Field (2009) the b values give the contribution of each predictor to the model. The standardized beta $(\beta)$ for OCB indicates that there is a positive impact from OCB on role conflict of operational employees, and the degree it affects is .773. It means that when OCB of operational employees increase by one standard deviation role conflict of them increase by .773 standard deviations. In addition, the probability of the $t$-statistic (13.331) for the standardized beta $(\beta)$ coefficient of OCB is significant at .00 which is less than the level of .05. Statistics relating to the regression testing Hypothesis 1 are depicted in Table 2 and 3.

"The smaller the value of Significance. (and the larger the value of $t$ ), the greater the contribution of that predictor" (Field, 2009, p. 239). Moreover, it 
was possible to conclude that there is a $60 \%$ of the variance in Role conflict of operational level employees is explained by organizational citizenship behavior alone. As there is a statistically significant impact from OCB on role conflict of operational level employees, Hypothesis 1 of the study is supported by the data in this study.

Table 04: Model parameters of sub hypotheses - Measuring the impact of sub hypotheses of organizational citizenship behavior on Role conflict.

\begin{tabular}{lclc}
\hline Model & $\begin{array}{c}\text { Standardized Coefficients } \\
\text { Beta }\end{array}$ & t & Sig. \\
\hline (Constant) & .070 & 3.797 & .000 \\
Altruism & .179 & .725 & .470 \\
Conscientious & .580 & 2.137 & .035 \\
Civic Virtue & .110 & 5.525 & .000 \\
Courtesy & .014 & 1.915 & .058 \\
Sportsmanship & .070 & .243 & .809 \\
\hline
\end{tabular}

Source: Survey Data (2016)

According to the output of dimensional analysis, only civic virtue was significant $(p=0.00<0.05)$ dimensions in OCB but other four dimensions were identified as insignificant for role conflict. Hence, civic virtue can be identified as the highly contributed dimension of OCB on role conflict of operational level employees in paint industry in Sri Lanka.

\section{Directions for Future Research}

For future research, several suggestions can be considered to provide a wider and in-depth research to measure the impact on Role Conflict. In the present study, researcher considers only the one of leading Paint Company in Sri Lanka. Future researchers can study to identify the impact of these factors for other industries as well. In this study, 150 Operational level employees were selected as the sample. But it is better increase the sample size for future studies. 


\section{Conclusion}

Organizational Citizenship Behavior was the independent variable and Role conflict was the dependent variable of the study. There were five dimension under the Organizational Citizenship Behavior and those are Conscientiousness, Sportsmanship, Civic Virtue Courtesy, and Altruism. There was a strong positive impact from Organizational Citizenship Behavior on Role conflict of operational level employees in paint industry in Sri Lanka. According to the analysis of the sub hypotheses of this study Sportsmanship, Conscientiousness Courtesy, Altruism Were rejected and only civic virtue was identified as a most influential factor on OCB. Hence mangers should have to pay special attention on civic virtue of organizational Citizenship Behavior and Role conflict before making their managerial decisions. Finally, the results of this study have important practical implications. They suggest that employers should attempt to understand how employees perceive the obligations within the employment relationship.

By understanding employees' perceptions of what they as employers are obligated to provide, they may avoid inadvertently violating those obligations. Further, if employers understand the psychological contracts held by their employees, they can try to alter the terms of those contracts if circumstances arise that make it impossible to fulfil promised obligations or if it becomes clear that misperception or miscommunication has occurred. By under- standing, and more importantly, attempting to manage, perceived obligations, organizations will be better able to ensure that their employees engage in OCB.

\section{Reference}

Argyris, C. (1976). Theories of action that inhibit individual learning. American Psychologist, 31(9), 638.

Barroso Castro, C., Martín Armario, E., \& Martín Ruiz, D. (2004). The influence of employee organizational citizenship behavior on customer loyalty. International journal of Service industry management, 15(1), 27-53.

Bensimon, E. M. (1993). Redesigning collegiate leadership: Teams and teamwork in higher education. Johns Hopkins University Press.

Biddle, B. J. T., \& Edwin, J. (1966). Role theory: Concepts and research 
Bolino, M. C., \& Turnley, W. H. (2005). The personal costs of citizenship behavior: the relationship between individual initiative and role overload, job stress, and work-family conflict. Journal of Applied Psychology, 90(4), 740.

Collis, J., \& Hussey, R. (2009). Business Research: Palgrave Macmillan.

Cortina, J. M. (1993). Interaction, nonlinearity, and multicollinearity: Implications for multiple regression. Journal of Management, 19(4), 915-922.

Costa, P. T., \& McCrae, R. R. (1992). Four ways five factors are basic. Personality and individual differences, 13(6), 653-665.

Deluga, R. J. (1998). Leader-member exchange quality and effectiveness ratings: The role of subordinate-supervisor conscientiousness similarity. Group \& Organization Management, 23(2), 189-216.

Field, A. (2009). Discovering statistics using SPSS. Sage publications.

Hair, J. F., Sarstedt, M., Ringle, C. M., \& Mena, J. A. (2012). An assessment of the use of partial least squares structural equation modeling in marketing research. Journal of the academy of marketing science, 40(3), 414-433.

Hooper, D., Coughlan, J., \& Mullen, M. (2008). Structural equation modelling: Guidelines for determining model fit. Articles, 2.

Jackson, S. E., \& Schuler, R. S. (1985). A meta-analysis and conceptual critique of research on role ambiguity and role conflict in work settings. Organizational behavior and human decision processes, 36(1), 16-78.

Kahn, R. L., Wolfe, D. M., Quinn, R. P., Snoek, J. D., \& Rosenthal, R. A. (1964). Organizational stress: Studies in role conflict and ambiguity.

Katz, D., \& Kahn, R. L. (1978). The social psychology of organizations (Vol. 2). New York: Wiley.

Kidder, D. L., \& Parks, J. M. (1993, August). The Good Soldier: Who Is S (he)? In Academy of Management Proceedings (Vol. 1993, No. 1, pp. 363-367). Academy of Management.

Kline, R. B. (2005). Methodology in the social sciences.

LePine, J. A., Erez, A., \& Johnson, D. E. (2002). The nature and dimensionality of organizational citizenship behavior: a critical review and meta-analysis. 
Lewis, J. D., \& Weigert, A. (1985). Trust as a social reality. Social forces, 63(4), 967-985.

Mayer, R. C., Davis, J. H., \& Schoorman, F. D. (1995). An integrative model of organizational trust. Academy of management review, 20(3), 709-734.

Organ, D. W. (1988). Organizational citizenship behavior: The good soldier syndrome. Lexington Books/DC Heath and Com.

Organ, D. W. (1997). Organizational citizenship behavior: It's construct clean-up time. Human performance, 10(2), 85-97.

Organ, D. W., \& Ryan, K. (1995). A meta-analytic review of attitudinal and dispositional predictors of organizational citizenship behavior. Personnel psychology, 48(4), 775-802.

Podsakoff, P. M., \& MacKenzie, S. B. (1994). Organizational citizenship behaviors and sales unit effectiveness. Journal of marketing research, 31(3), 351-363.

Podsakoff, P. M., Ahearne, M., \& MacKenzie, S. B. (1997). Organizational citizenship behavior and the quantity and quality of work group performance. Journal of applied psychology, 82(2), 262-269.

Podsakoff, P. M., MacKenzie, S. B., Paine, J. B., \& Bachrach, D. G. (2000). Organizational citizenship behaviors: A critical review of the theoretical and empirical literature and suggestions for future research. Journal of management, 26(3), 513-563.

Rizzo, J. R., House, R. J., \& Lirtzman, S. I. (1970). Role conflict and ambiguity in complex organizations. Administrative science quarterly, 150-163.

Saunders, M. N. (2011). Research methods for business students, 5/e. Pearson Education India.

Smith, C. A., Organ, D. W., \& Near, J. P. (1983). Organizational citizenship behavior: Its nature and antecedents. Journal of applied psychology, 68(4), 653.

Walsh, J. P. (1988). Selectivity and selective perception: An investigation of managers' belief structures and information processing. Academy of Management journal, 31(4), 873-896. 